\title{
CONSCIÊNCIA AMBIENTAL, PRINCÍPIOS E INDICADORES DE QUALIDADE DE VIDA: UM ESTUDO NO CAMPO DA CLIMATOLOGIA URBANA
}

\author{
Clêane Oliveira dos Santos ${ }^{8}$ \\ Josefa Eliane Santana de Siqueira Pinto ${ }^{9}$
}

\begin{abstract}
RESUMO
A preocupação com a dimensão ambiental está associada à busca de estratégias que visam atuar no âmbito da gestão e ordenamento do território, possibilitando a busca de novos conceitos, métodos de ação e investigação mais abrangentes e globalizantes na esfera dos recursos naturais e aglomerados urbanos. Neste artigo, objetiva-se analisar a possível influência do ambiente construído e das áreas verdes na qualidade de vida do município de Itabaiana/SE. Para tal, realizou-se revisão bibliográfica com leitura, fichamento e análise de livros, teses, dissertações e artigos sobre temas como qualidade de vida, qualidade ambiental, clima, áreas verdes e questões socioambientais. Efetivou-se pesquisa de campo para averiguação das condições atmosféricas locais e presença e disposição de áreas verdes, e para aplicação de entrevistas, no intuito de analisar o grau de desenvolvimento da consciência ambiental cidadã. Foram organizadas questões semi-estruturadas abrangendo a percepção da importância, da intensidade e da interferência da arborização no clima como um todo, e no conforto térmico da cidade. A guisa de resultados tem-se que o espaço construído e a insuficiência de áreas verdes no município atuam sobre a temperatura e a umidade. Além disso, a construção e substituição da superfície natural por um conjunto de construções de imóveis aumentam a rugosidade, cujos efeitos mais diretos são: a redução da velocidade do vento e aumento da turbulência, verificados especialmente no bairro Centro. A arborização é o componente ambiental mais visível, contudo a população ainda não tem plena consciência sobre a importância da conservação das áreas verdes para a qualidade ambiental do espaço vivido na cidade, uma vez que nesses espaços se efetivam as relações sócio-culturais dos itabaianenses, para eles, uma questão de sobrevivência maior. Logo, percebe-se que a população e autoridades não possuem uma identidade voltada para questões ambientais, isto é, a sociedade

8 Mestre em Geografia pelo Núcleo de Pós-Graduação em geografia da Universidade Federal de Sergipe NPGEO/UFS. Tutora do Centro de Educação Superior à Distância, CESAD/UFS. cle.ufs@hotmail.com

9 Doutora em Geografia. Professora do Departamento e Núcleo de Pós-Graduação em Geografia da Universidade Federal de Sergipe, DGE/NPGEO/UFS. josefaeliane@ufs.br
\end{abstract}


não se preocupa e não se manifestam se essas questões vão influir ou não na qualidade de vida municipal.

Palavras-chave: Ambiente construído, Consciência ambiental, Qualidade de vida.

\section{ABSTRACT}

Concern about the environmental dimension is associated with the search for strategies that aim to act in the management and planning, enabling the search for new concepts, methods and action research more comprehensive and globalizing the sphere of natural resources and urban settlements. In this article aims to analyze the possible influence of the built environment and green areas in quality of life in the city of Itabaiana/Se. To this end, we carried out reading literature review, fingerprinting and analysis of books, theses, dissertations and articles on topics such as quality of life, environmental quality, climate, green areas and socio-environmental issues. Was accomplished field research to investigate the local atmospheric conditions and the presence and arrangement of green areas, and the application of interviews in order to analyze the degree of development of environmentally conscious citizens. Were organized semistructured questions covering perceptions of the importance, intensity and the interference of trees in climate as a whole, and thermal comfort of the city. The way of results is that the built environment and lack of green areas in the city act on the temperature and humidity. Moreover, the construction and replacement of the natural surface by a set of constructions of buildings increase the roughness, the effects are more direct: the reduction of wind speed and increased turbulence, especially checked in Downtown. The afforestation is the most visible environmental component, yet the population still not fully aware of the importance of conservation of green areas for the environmental quality of living space in the city, since these spaces are characterized the socio-cultural relations of itabaianenses, for them, a matter of survival greater. Soon, you realize that people and authorities have no identity toward environmental issues, that is, society does not care and do not manifest these issues will influence whether or not the quality of municipal life.

Keywords: Built environment, Environmental awareness, Quality of life.

\section{INTRODUÇÃO}

O mundo evolui desigual e heterogêneo. Assim, suscinta a necessidade de análise dos aspectos ligados à vulnerabilidade socioambiental para que, através deles, sejam estruturadas melhores condições de vida à população. Porém, sabe-se que não é fácil definir uma boa condição de vida bem como os seus parâmetros e indicadores, pois neles estão contidos fatores subjetivos e objetivos.

Além disso, considera-se importante a realização de uma análise combinada entre os fatores ambientais, sociais e culturais para compreender os aspectos socioambientais de uma dada localidade, sendo esta relevante para o 
estabelecimento de medidas que dêem condições dignas de vida à população no meio em que se vive.

A preocupação com a dimensão ambiental está associada à busca de estratégias que visam atuar no âmbito da gestão e ordenamento do território, possibilitando, desta forma, buscar novos conceitos e métodos de ação e investigação mais abrangentes e globalizantes na esfera dos recursos naturais e aglomerados urbanos.

É indiscutível a necessidade de reflexões teóricas com base em experiências científicas e acadêmicas de geógrafos e cientistas afins nas questões que envolvem o nível epistemológico, metodológico e empírico. Desse modo, a análise da qualidade ambiental não deve estar somente reservada à natureza e ao ecossistema, pois engloba elementos da atividade humana com reflexos diretos na vida do homem.

Considera-se que o estímulo a uma pesquisa vincula-se, direta ou indiretamente, ao contexto mais amplo que esteja vinculada qualquer pesquisa cientifica. Nesse sentido, o posicionamento diante de questões que envolvem o objeto de pesquisa é condição para seu desenvolvimento.

Diante de tal fato, neste artigo, objetiva-se analisar a possível influência do ambiente construído e das áreas verdes na qualidade de vida no campo abrangente do espaço urbano de Itabaiana/SE.

A imagem da cidade hoje reproduz um debate sobre a interação entre a sociedade e a natureza à luz da discussão ambiental em decorrência da relação entre o natural e o social que produz o espaço geográfico. Assim, as causas da degradação ambiental e da crise da relação sociedade/natureza não surgem somente do instinto perverso do homem, e as conseqüências de tal degradação não se dão apenas pelo uso inadequado dos recursos naturais, são frutos de um conjunto formado pelo capitalismo, modernidade, industrialização e urbanização.

Nesse sentido, "a cidade, não é somente uma construção humana; ela é esta construção somada a todo um suporte que a precedeu - Natureza - mais as atividades humanas" (MENDONÇA, 2004, p. 185). Resultados de tal construção surgem ambientes urbanos com dimensões diferentes para 0 desenvolvimento humano, seja através da boa condição ou a partir de ambientes desagradáveis e problemáticos, os quais representam grandes porções do espaço das cidades.

Ao longo da história das cidades criaram-se também debates, concepções e percepções diversas sobre a urbanização das cidades, porém no presente é importante observá-la através do aspecto interativo ou como um campo intermulti-transdisciplinar, pois "o horizonte histórico-cultural deste debate está irremediavelmente atravessado por uma multiplicidade de interesses e projetos sociais que vão disputar diferentes interpretações sobre o ambiental" (GUIMARÃES, 2003, p. 81).

Recorrendo a literatura constata-se que umas das primeiras iniciativas que tratou a cidade sob um ponto de vista sistêmico, abordando o clima, como um dos elementos formadores da cidade foi Carlos Augusto Monteiro em 1976 com a construção do Sistema Clima Urbano, mostrando que a cidade é fruto de um campo de interações ente a natureza e a sociedade.

É nesta perspectiva que a concepção de ambiente urbano se desenvolve, uma vez que, todo um complexo fluxo de matéria e energia, de origem natural e/ou produto da ação humana, interage permanentemente no contexto urbano e 
dinamiza as formas com que se manifestam os elementos da natureza e da sociedade na cidade, formando a materialidade urbana (MENDONÇA, 2004).

$O$ ambiente atmosférico influencia o homem e suas atividades, enquanto o homem pode, a partir de suas ações, consciente ou inconscientemente influenciar o tempo e o clima. Este talvez seja o mais importante elemento do ambiente natural, pois as principais bases da vida para a humanidade estão na dependência do clima, especialmente o ar, a água, o alimento e o abrigo.

Desde o século XVIII o estudo do clima das cidades e, conseqüentemente, da qualidade do ambiente urbano vem despertando grande interesse. Estudos clássicos de clima urbano apontaram evidências de alterações de elementos climáticos nos centros urbanos, visto que cada construção converte em calor, de forma diferente, a radiação solar que entra no sistema.

Dessa forma, constrói-se um microclima, ou seja, um tipo de clima local que é um ponto dentro do regional onde uma conjunção de fatores das diversas esferas do domínio geográfico especializa uma dada definição climática, fato que nos reporta à questão das escalas do clima, a zonal, a regional e a local.

Os problemas resultantes das modificações antropogênicas no Sistema Climático são evidenciados de modo mais eficiente nas áreas urbanas, onde se tem uma dificuldade de dissociar os atributos climáticos dos elementos de qualidade ambiental, pois ambos são componentes do sistema urbano, intimamente relacionados e dependentes entre si.

O meio ambiente urbano é um sistema intimamente inter-relacionado, em que tanto os elementos antrópicos quanto os naturais são considerados parte do sistema de relações, e a qualidade de vida ou não é fruto da associação dos dois. Por tal razão o clima da cidade representa um sistema aberto, implicando, portanto, em entrada de energia, sua transformação no sistema e exportação ao ambiente externo.

A cidade é o espaço em que a atuação do homem se manifesta na transformação da paisagem natural. Considerando o sistema atmosférico, o espaço urbano é aquele disposto entre o solo e os telhados dos edifícios, onde o impacto das construções e das atividades urbanas interfere na morfologia urbana e nas condições climáticas.

O clima urbano é, pois, a modificação substancial de um clima local, sendo variável, segundo a concentração populacional e/ou a densidade de edificações. Assim as alterações no conforto térmico dependem dos tipos de tempo e da estrutura urbana (PINTO E AGUIAR NETTO, 2008).

$A$ intensa e crescente urbanização que vem ocorrendo nas cidades tem modificado os aspectos do clima local, prejudicando o conforto térmico. A desordenada ocupação do solo, o aumento de áreas construídas e o adensamento populacional, associados à redução de espaços verdes intraurbanos e à poluição atmosférica, têm causado alterações no microclima das cidades, tais como elevação da temperatura e umidade do ar e mudança da direção e velocidade dos ventos.

Desse modo, o padrão da estrutura urbana representada pelos usos do solo, traçado da rede viária, densidade e altura das construções, materiais da construção, altura e orientações das edificações, asfalto, posição orográfica, sítio urbano e morfologia contribuem de forma direta e indireta para o bem estar coletivo da população das cidades sejam elas grandes, médias ou pequenas. 
Pode-se inferir, por conseguinte, que a qualidade de vida e o conforto são afetados mais pelo clima do que qualquer outro componente do meio ambiente, já que as funções fisiológicas do homem respondem às mudanças no tempo atmosférico.

Ayoade (1991) informa que o vigor físico do homem é influenciado pela temperatura, umidade e vento. Geralmente a alta temperatura e a umidade tendem a abrandar a força física e o mental. $O$ ar seco ou temperaturas extremamente baixas podem prejudicar ou diminuir a energia física e a disposição para o trabalho mental.

Em tal perspectiva, os efeitos resultantes do impacto das construções e das atividades urbanas são sentidos em esferas da vida tais como: conforto térmico, qualidade e circulação do ar, pluviosidade concentrada, desorganização da vida urbana, transtornos no deslocamento urbano, desmoronamentos, surgimento de desabrigados, doenças endêmicas, distúrbios de coração, de circulação, de respiração e dermatológicos, transtornos de humor e adequação do vestuário.

Ainda segundo Pinto e Aguiar Netto (2008) o espaço construído atua sobre a temperatura e umidade como consequência da substituição da superfície natural e permeável por um conjunto de edificações e superficies impermeáveis que aumentam a rugosidade, diminuem a velocidade dos ventos, são boas condutoras de calor e de redução do albedo. Desse modo, o escoamento superficial se acelera e a evaporação se reduz, provocando aumento de calor.

A temperatura é a variável mais afetada e a que melhor caracteriza o clima das cidades, pois há uma tendência de se armazenar energia na alvenaria das edificações, no asfalto e no concreto, devido à grande condutibilidade térmica de seus materiais.

A presença de áreas verdes é essencial na estrutura e dinâmica do ambiente urbano, que por seus atributos, vem colaborar para a melhoria da qualidade ambiental e de vida da população, a partir dos benefícios desempenhados pelas funções naturais da vegetação arbórea.

Nessa perspectiva se destaca a importância das áreas verdes e sua influência no comportamento do microclima urbano, a fim de mitigar os efeitos prejudiciais da urbanização e na melhora das condições ambientais em áreas urbanizadas. Portanto, as plantas, sobretudo as arvores, têm a função de extrair água do solo para devolvê-la ao ar, auxiliando na manutenção do equilíbrio climático ao produzir sombreamento e filtrar grande quantidade de radiação solar que alcançaria a superfície.

Segundo Lorusso (1992) as áreas verdes urbanas englobam três setores individualizados que estabelecem interfaces entre si, são as áreas verdes públicas representadas pelos logradouros públicos destinados ao lazer ou que viabilizam o encontro direto da população com a natureza. As áreas verdes privadas constituídas pelos remanescentes vegetais incorporados à malha urbana, tais como as coberturas verdes presentes nos fundos de quintais e em clubes particulares. Além da arborização viária presente nas ruas e avenidas.

Assim, áreas verdes podem ser definidas como um conjunto de subespaços (públicos e privados) e logradouros das cidades constituídos de vegetação de distintos estratos, devendo ser providos de elementos de porte arbóreo, seja de ordem natural ou implantada, sendo caracterizado por solos permeáveis (REZENDE; MELO E SOUZA, 2009).

A implantação desses espaços deve ocorrer com base em parâmetros 
que favoreçam o seu melhor aproveitamento para o conforto urbano. Por conseguinte, a análise das temperaturas, dos ventos predominantes, da umidade relativa do ar, da topografia e das características da população indicará a localização, dimensão, uso e equipamentos de áreas verdes. A previsão de um sistema verde que permeie a malha urbana é, portanto, essencial para o conforto e a qualidade de vida nas cidades.

Lima Neto e Melo e Souza (2009) afirmam que o equilíbrio da arborização no meio urbano promove resultados benéficos no instante em que exerce função estética, social e ecológica no sentido de embelezamento da cidade, melhoria do ambiente urbano e bem estar na sociedade.

A função estética está relacionada ao contraste harmônico entre as estruturas de concreto versus a forma de densidade dos elementos arbóreos, apresentando assim um valor estético com alto nível de desconstrução da poluição visual produzidos pelos outdoors, faixas, e construções de diferentes estilos arquitetônicos.

A funcionalidade social da arborização no meio urbano está voltada para o relacionamento da sociedade, uma vez que a presença de árvores possibilita a oportunidade de convívio entre pessoas de diferentes classes sociais em espaços verdes públicos, sendo essencial para o bem-estar psíquico em termos de atenuação do estresse.

A função ecológica está presente no verde urbano, representado pelo extrato arbóreo e pela vegetação rasteira. Desempenha uma ação purificadora por fixação das poeiras e matérias residuais, realiza, também, a reciclagem de gases tóxicos através da ação natural fotossintética, além de colaborar na depuração bacteriana e de outros organismos, melhorando a qualidade do ar (REZENDE; MELO E SOUZA, 2009).

Sob perspectiva ecológica, a arborização urbana melhora o microclima, por meio da redução da incidência de raios solares, da elevação da umidade atmosférica e da conseqüente amenização das temperaturas.

Nos centros urbanos, as áreas verdes funcionam como indicadores para conhecer e avaliar as questões ambientais e suas interferências na qualidade de vida da população. Por isso, a presença da cobertura vegetal em cada bairro da cidade é um dos parâmetros que trazem benefícios diretos e indiretos para o conforto térmico e qualidade do ar na área urbana.

De acordo com Nucci (2001) no contexto atual para a maioria das pessoas as funções da cobertura vegetal atendem mais a satisfação psicológica e cultural do que as funções físico-biológicas. No entanto, a cobertura vegetal das áreas verdes urbanas exerce influencia significativa na qualidade ambiental e no bem estar dos habitantes, muito além do valor estético e/ou sentimental.

Parafraseando Lima Neto e Melo e Souza (2009):

A arborização em cidades aparece com o intuito de garantir um arranjo do homem com o ambiente natural, a fim de desfrutar seus principais benefícios inerentes ao bem-estar que estão diretamente vinculados ao componente vegetal, atendendo ao aspecto cultural e psicológico do ser humano. Ela é representada por conjuntos arbóreos de diferentes origens e que desempenham diferentes papeis e tem desempenho no restabelecimento da relação entre o homem e o meio natural, garantindo melhor qualidade de vida (LIMA NETO; MELO E SOUZA, 2009, p. 56). 
No âmbito dessa discussão destaca-se a impossibilidade de resolver os crescentes e complexos problemas ambientais e reverter suas causas sem que ocorra uma mudança radical nos sistemas de conhecimento, dos valores e dos comportamentos produzidos pela dinâmica de racionalidade existente, fundada no aspecto econômico do desenvolvimento.

\section{MATERIAL E MÉTODOS}

Realizou-se revisão bibliográfica com leitura, fichamento e análise de livros, teses, dissertações e artigos sobre temas como qualidade de vida, qualidade ambiental, conforto térmico, áreas verdes e questões socioambientais.

Efetivou-se, também, pesquisa de campo para conhecimento das condições atmosféricas locais e presença e disposição de áreas verdes. Efetivouse, também, aplicação de entrevistas, nas quais foram organizadas de forma semi-estruturada questões que abrangeram parâmetros sobre a percepção da importância, da intensidade e da interferência da arborização no conforto da cidade. Uma vez que, a percepção da população quanto aos benefícios trazidos por uma arborização adequada das áreas urbanas tem sido utilizada em alguns bairros ou cidades do Brasil.

Vale ressaltar que essa ferramenta de pesquisa até então não havia sido explorada em Itabaiana/SE, município que dispõe de alguns espaços urbanos verdes que devem ser preservados.

\section{RESULTADOS E DISCUSSÕES}

Essa pesquisa tem como área de estudo o município de Itabaiana, situado na latitude de $10^{\circ} 41^{\prime} 06^{\prime \prime}$ Sul e de longitude de $37^{\circ} 25^{\prime} 31^{\prime \prime}$ Oeste, centrado na faixa centro-ocidental do estado de Sergipe (figura 01). Além disso, município ocupa uma extensão territorial de $336,9 \mathrm{~km}^{2}$, representando 1,53\% do território sergipano. Possui 52 povoados e sua sede municipal distancia-se da capital do estado, Aracaju, em 56 km.

O território de Itabaiana destaca-se no contexto sergipano, em função da localização geográfica. De acordo com a Secretaria de Estado do Planejamento e da Ciência e Tecnologia (SEPLANTEC), 1997/2000, está parcialmente inserido no polígono das secas, configurando-se numa região de transição climática, o agreste sergipano, fato que a torna peculiar no contexto de Sergipe, pois apresenta vulnerabilidades ambientais. Por outro lado ainda é possível constatar a presença de ambientes intactos, preservados, indicando a potencialidade ambiental do município, a exemplo do Parque Nacional Serra de Itabaiana, situado próximo à costa de Sergipe $\left(10^{\circ} 40^{\prime} \mathrm{S}, 37^{\circ} 25^{\prime} \mathrm{W}\right)$, abrange uma área de 7966 ha compreendendo três unidades, as serras Cajueiro, Comprida e a de Itabaiana, a maior delas. 


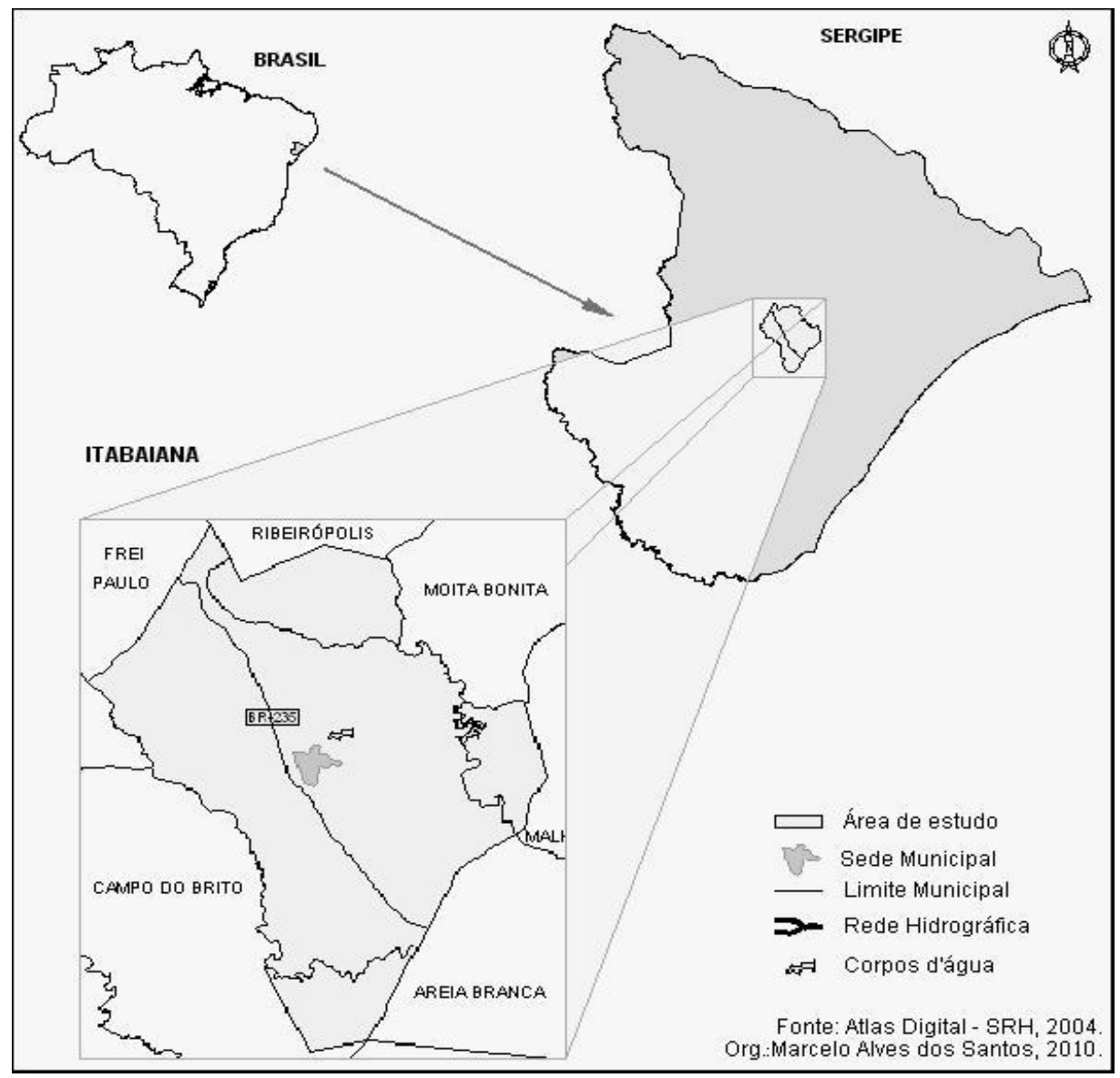

Figura 01. Localização da área de estudo.

Nas palavras de Ab' Saber (1999):

O conceito de agrestes é bem mais complexo do que o de brejos na geografia dos espaços ecológicos do Nordeste. Em termos muito genéricos, os agrestes constituem uma faixa de transição climática, sob a forma de tampão, entre a zona da mata oriental do Nordeste e os imensos espaços dos sertões secos. Não é uma faixa muito larga, tampouco muito homogênea, comportando, do ponto de vista topográfico, uma grande variedade de formas e compartimentos. Nos agrestes chove mais do que nos sertões, porém bem menos do que na zona da mata ( $A B^{\prime}$ SABER, 1999, p. 17).

O clima de qualquer região é determinado, sobretudo, pela circulação geral da atmosfera, que por sua vez resulta do aquecimento diferencial do globo pela radiação solar, da distribuição assimétrica de oceanos e continentes, das características edáficas e topográficas, de sua densidade biogeográfica, além da condição astronômica e latitudinal.

De acordo com o Atlas Escolar de Sergipe (2007) em Sergipe as temperaturas médias são elevadas e representam uma das particularidades do 
clima, pois obedecem aos controles físicos como a baixa latitude, as correntes marinhas ao longo do litoral, os efeitos topográficos e a continentalidade, todos relacionados aos sistemas de circulação atmosférica.

É importante destacar que a maior parte dos municípios de Sergipe apresenta deficiência hídrica quase todo o ano, principalmente na primavera e verão. No município de Itabaiana não acontece diferente, ocorrem excedentes de chuvas nos meses de maio, junho e julho, período em que se observa um decréscimo de temperatura, prolongando-se até final do mês de agosto. A regularidade das precipitações concentradas no mês de maio é assegurada pela atuação da Frente Polar Atlântica, que é responsável pela intensidade das chuvas, e pelas Correntes Perturbadoras do Leste.

Assim Itabaiana apresenta índices de precipitações anuais que vão desde $1300 \mathrm{~mm}$ na pequena porção do Litoral úmido e constantes de 900 a $1200 \mathrm{~mm}$ na faixa do agreste municipal, onde se verifica um decréscimo das precipitações com o afastamento da fonte de suprimento de umidade no oceano (figura 02).

A interface clima/sociedade pode ser entendida em termos de ajustamento, já que "a relação do homem com o clima nem sempre ocorre pacificamente, pois, ao lado dos benefícios, a atmosfera também traz prejuízos significativos, tornando, algumas vezes e em alguns lugares, a convivência bastante problemática" (PINTO, 1999, p.11).

Não obstante, a idéia do clima de um lugar, que dá origem à expectativa de seu próprio comportamento, é elaborada pela tradição, representada pela transmissão oral de usos e costumes, aliada à vivência do dia a dia das pessoas. Logo, a perspectiva de relação e dependência dos seres vivos em relação ao clima, a capacidade de adaptação e o emprego de tecnologias para uso mais racional de recursos disponíveis, atesta que o homem é de fato um ser integrado ao meio (PINTO, 2006).

Cabe destacar que municípios médios e pequenos apresentam, em níveis inferiores aos grandes, problemas ambientais e queda de qualidade ambiental que se agravam na medida em que a urbanização se intensifica. Desse modo, o tema das condições de vida é hoje uma preocupação generalizada de toda a sociedade. Porém, o lugar principal no qual esta preocupação se materializa é o município, menor unidade da estrutura política - administrativa brasileira e onde, em tese, a oferta de uma qualidade de vida deveria ser mais facilitada.

Em Itabaiana, o bairro Centro é exemplo de espaço construído no conjunto urbano que vem a se constituir o centro econômico do município, e onde também se concentra o maior número de sobrados, com até dois pavimentos. Tal fato mostra uma tendência a pouca circulação de ventos na área, como também um aumento da temperatura em virtude das ruas se apresentarem estreitas e asfaltadas, o que agrava o desconforto térmico da cidade, pois, mudanças na velocidade e na orientação dos ventos tendem a ser freadas pelos sobrados.

Assim, há desconforto térmico que tende a ser mais acentuado na área comercial, onde há concentração maior no número de sobrados, uma vez que o itabaianense, por vezes, mantém seu comércio e moradia no mesmo edifício. Vale salientar que a geometria dos edifícios em uma cidade pode implicar no aprisionamento do ar e constituir superfícies ásperas.

De manhã, as paredes das construções expostas diretamente ao sol apresentam temperaturas mais elevadas que a dos telhados e as das áreas rurais em torno. O calor acha-se concentrado entre as paredes das ruas mais 
estreitas. Ao meio dia, os telhados e as áreas estão bem aquecidos, ao passo que as paredes não expostas apresentam temperaturas menos elevadas. $\mathrm{E}$ durante a noite, as edificações liberam a energia acumulada durante o dia, funcionando como bolsas de água quente, irradiando energia em várias direções.

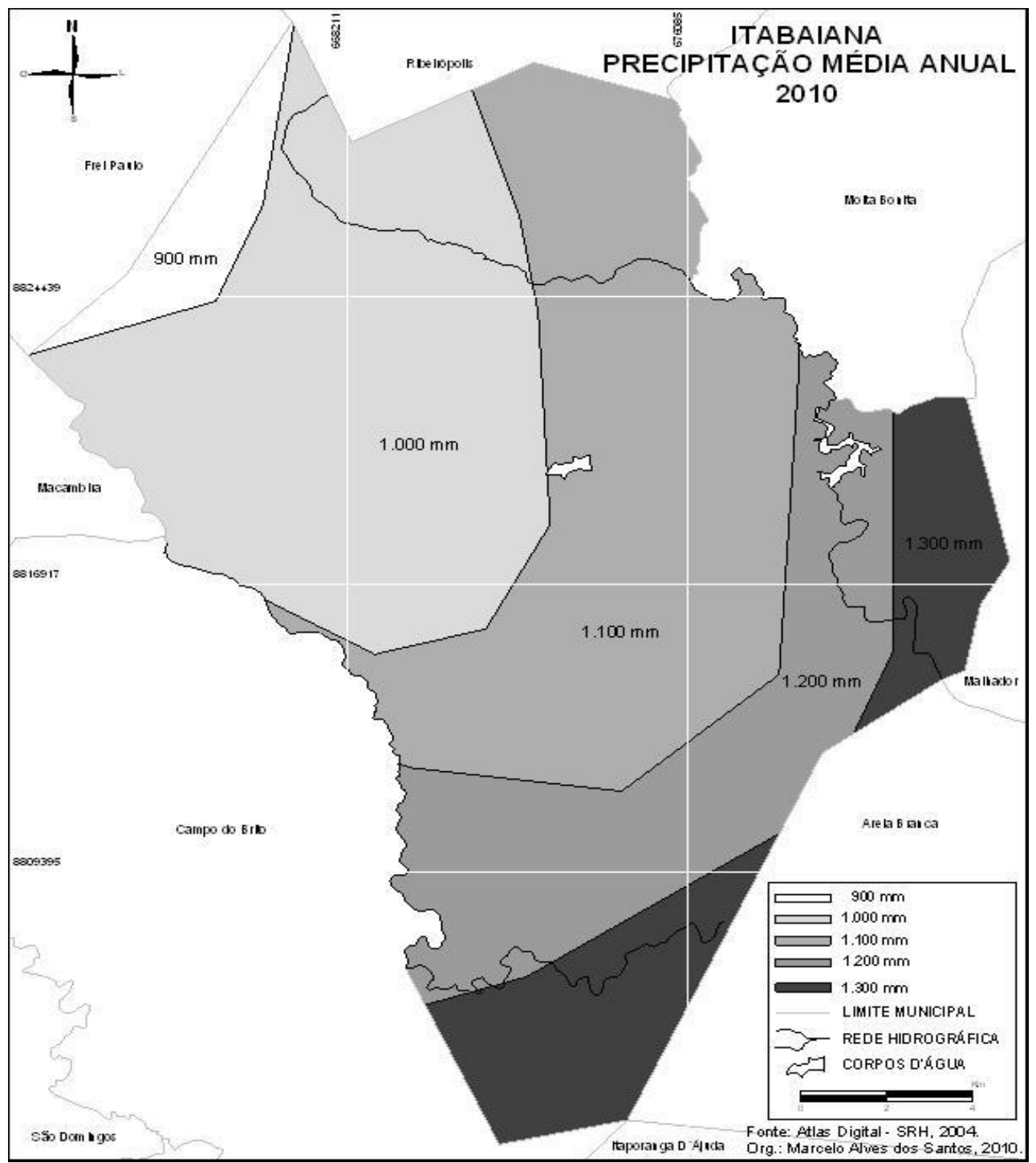

Figura 02. Distribuição da precipitação média anual no município de Itabaiana-SE.

O centro comercial de Itabaiana é totalmente pavimentado, com presença de apenas quatro praças com árvores de mais de cem anos. Contudo, a arborização é um fator considerável para a qualidade de vida humana. Além da função paisagística, proporciona outros benefícios ao homem. Produz sombra, diminui a intensidade dos ruídos, melhora a qualidade do ar, reduz o calor e o frio, embeleza a paisagem e valoriza o espaço em que está inserida, 
proporciona sensação de contato com a natureza, oferece abrigo e alimento a pequenos animais, favorecendo a biodiversidade.

A presença de vegetação de porte arbóreo é fundamental em praças, parques, jardins públicos, bem como em canteiros e na rede viária, pois desempenha múltiplos benefícios a saúde humana associados à melhoria da qualidade ambiental. Quando avaliados acerca da importância da arborização numa cidade, $38 \%$ apontaram a escala máxima, considerando uma escala de 1 a 5 em nível de importância crescente, como pode ser verificado na figura 03 .

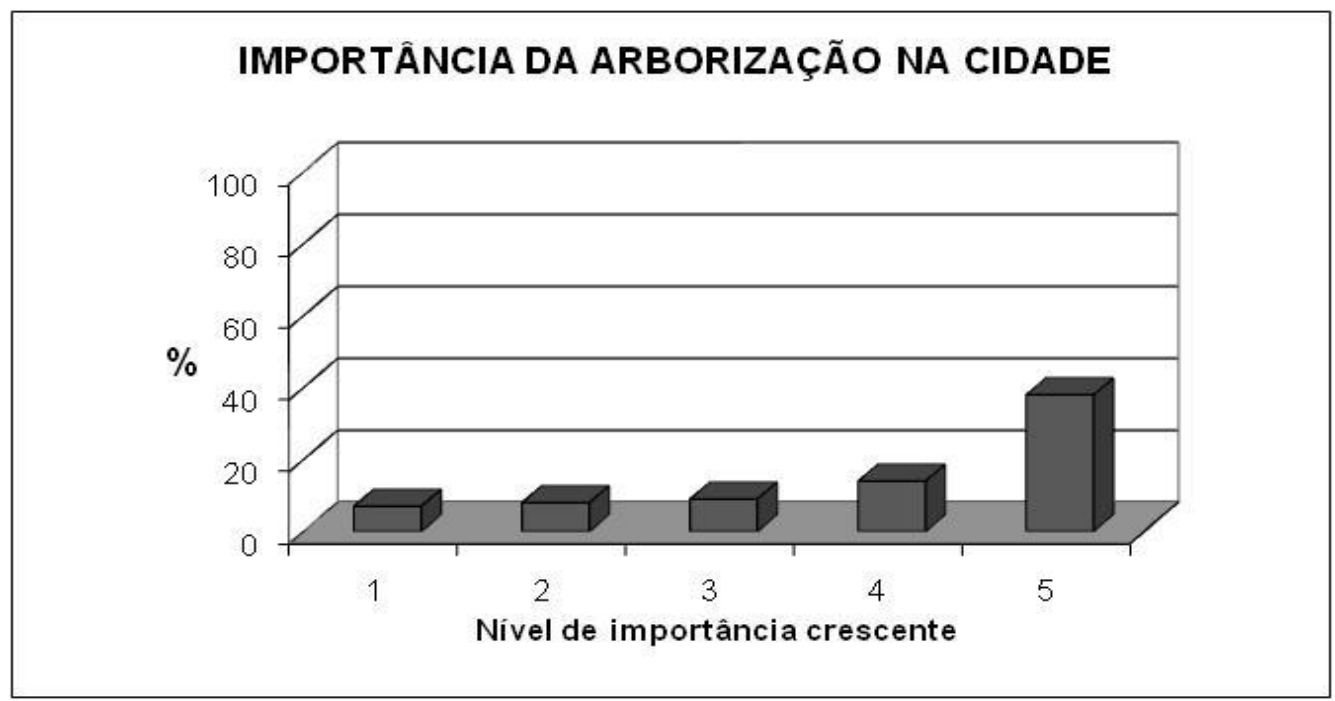

Figura 03. Importância da arborização na cidade.

Organização: Clêane Oliveira dos Santos, 2009.

Fonte: Pesquisa de campo, 2009.

Esse fato pode estar ligado à questão do desconforto térmico que se forma no bairro centro onde se dá um maior fluxo de pessoas e tráfego de automóveis de pequeno, médio e grande porte, sendo enfática nos dias de feira, quando se concentram cerca de 25.000 pessoas nessa área, ou ainda nas quintas-feiras, devido à concentração de veículos para embarque e desembarque de mercadorias nos Largos São Antônio e Largo José do Prado Franco. Logo, em virtude de tantos fluxos há períodos do dia, onde o calor torna-se acentuado, onde o padrão de circulação da cidade agrava a poluição pela direção convergente dos ventos em decorrência das diferenças barométricas e pelo estabelecimento de uma camada de inversão.

Em Itabaiana os espaços verdes estão distribuídos em áreas pontuais da cidade, especificamente nos canteiros das principais avenidas e nas praças localizadas, em diferentes graus de intensidade, tanto no centro da cidade quanto em bairros mais afastados. Predomina espécies de valor decorativo ainda que climaticamente adaptadas. As espécies vegetais nativas foram desmatadas ao longo do tempo, sem reservas no entorno urbano.

A cidade é constituída de doze praças que são as seguintes (figura 04): Praça Fausto Cardoso, João Pessoa, General João Perreira, São Luiz, João Marcelo, Lafaete Noronha, Padre Gumercindo, Oliveira, Vesta Maria de Góis, Frei Fidelis, Jubal de Carvalho, Calçadão Francisco Teles de Mendonça. No entanto, a população ainda não atribui o correto valor a esses espaços que muitas vezes 
são degradados em decorrência da falta de consciência e educação ambiental.

A avaliação dos dados diagnosticou, também, a percepção da intensidade de áreas verdes nas ruas e calçadas da cidade, considerando uma escala de muito alta, média e muito baixa; $54 \%$ afirmaram que as praças possuem uma intensidade muito alta de áreas verdes, percentual inferior aos $72 \%$ que associaram às calçadas a intensidade muito baixa de áreas verdes é muito baixa.

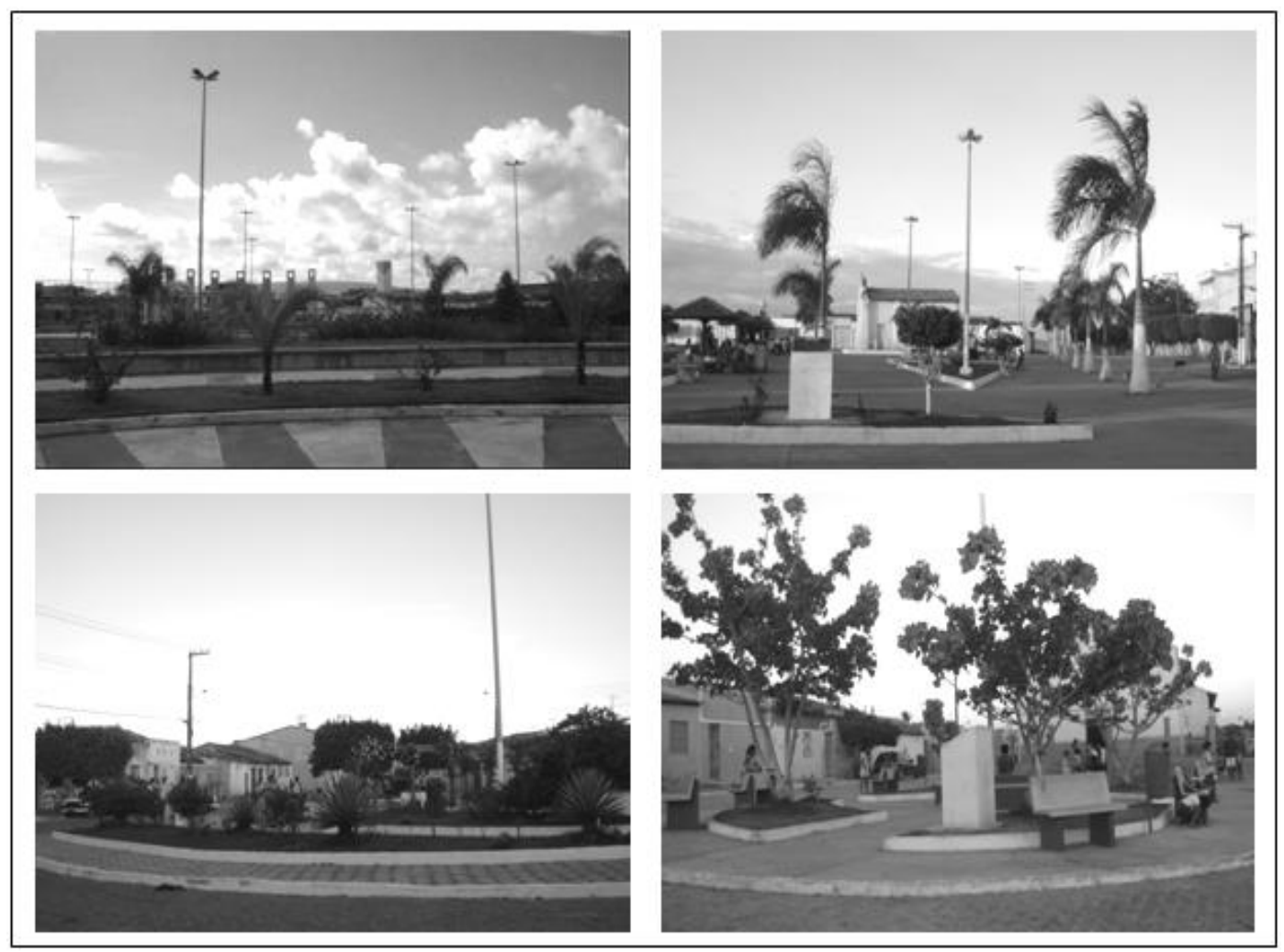

Figura 04. Praças presentes em Bairros distintos de Itabaiana.

Foto: Clêane O. dos Santos, 2010.

Verificou-se no município que o índice de área verde pública por habitante (IAVP/hab) revela uma carência de arborização em espaços públicos, onde se constatou uma carência de vegetação arbórea, que associada ao amplo adensamento populacional resulta em um baixo índice a ponto de não atingir $1 \mathrm{~m}^{2}$ de verde/hab, quando a referência indicada pela Sociedade Brasileira de Arborização Urbana (SBAU) é de no mínimo $15 \mathrm{~m}^{2}$ de área verde/habitante.

Vale salientar que de acordo com dados coletados por questionário 30 pessoas consideraram Itabaiana arborizada, porém 67 pessoas afirmaram que a cidade ainda necessita de árvores, sobretudo, porque a mesma passou por um processo de pavimentação (asfalto), e 3 pessoas não souberam diagnosticar tal fato.

Assim, observa-se que os entrevistados associam a presença de árvores com a redução do desconforto térmico ocasionado pelo conjunto da estrutura urbana presente. No entanto, uma significativa parcela da população não se preocupa ou não tem consciência da preservação dos poucos espaços verdes 
existentes na cidade, uma vez que é constante a prática de deposição de lixo e retirada banal de plantas dos espaços públicos.

Explica a ciência que para a manutenção das áreas verdes em bom estado é necessário cuidados constantes, desde a condução das mudas em crescimento, até a recuperação de árvores antigas passando pela limpeza dos espaços. As podas, quando necessárias, devem obedecer a critérios técnicos e serem feitas corretamente, para evitar danos à árvore e não prejudicar sua beleza e sua contribuição de sombra no espaço.

É importante ressaltar que apesar da existência de um significativo número de praças na cidade, verifica-se que em algumas não existe arborização, no máximo observam-se gramados e pequenas plantas, a exemplo de praças localizadas em bairros periféricos da cidade (Figura 05).

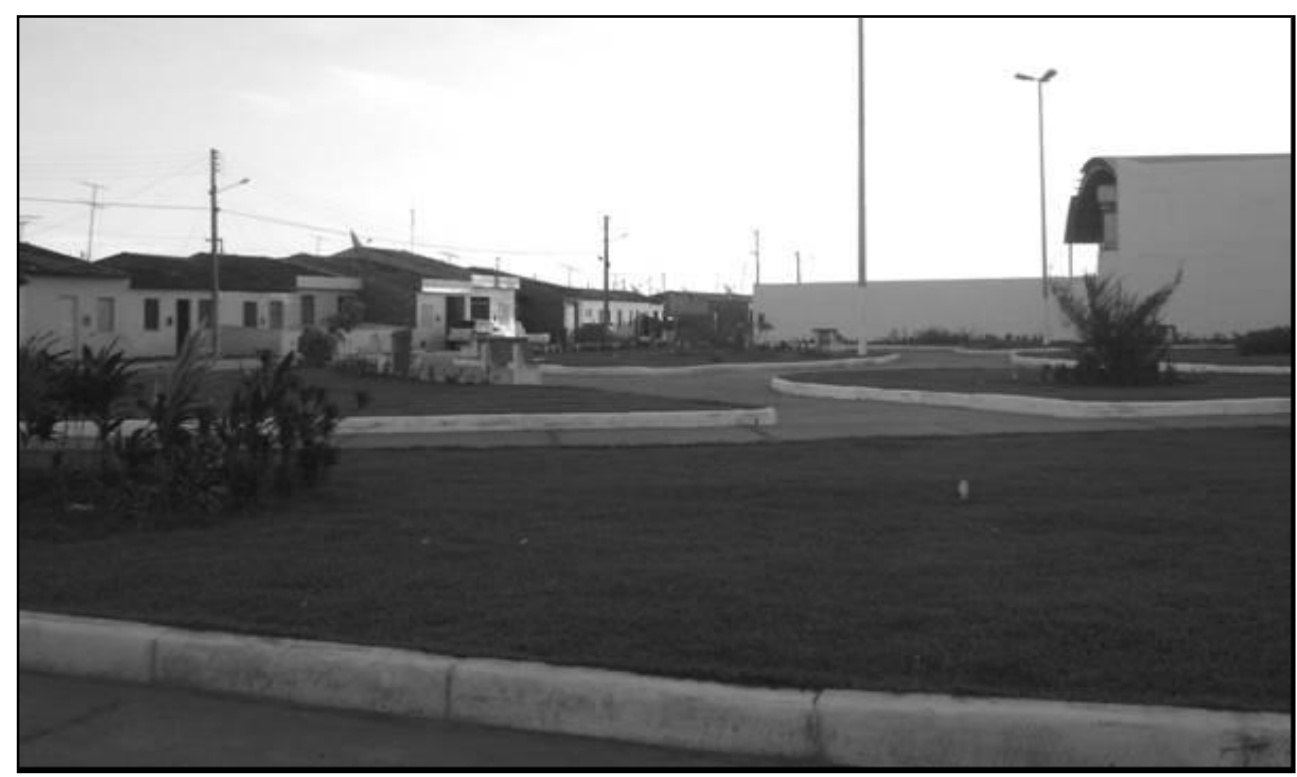

Figura 05. Vista da Praça do bairro São Cristóvão.

Foto: Clêane Oliveira dos Santos, 2009.

O espaço ocupado por áreas verdes na cidade afeta não somente a paisagem da cidade, mas, também, a qualidade ambiental, representando alterações significativas nos padrões de circulação das massas de ar, podendo levar a possíveis mudanças no seu microclima, e no sistema de drenagem local. No entanto, essas áreas são importantes, dentre outros motivos, porque permitem que a água da chuva penetre no solo, alimentando o lençol freático, evitando que esta água se acumule sobre a área coberta por materiais impermeáveis e cause transtornos socioambientais.

\section{CONSIDERAÇÕES FINAIS}

As atividades humanas, se não realizadas com disciplina e de acordo com os adequados parâmetros urbanísticos e ambientais, provocam danos ao meio ambiente, com sacrifício à qualidade de vida da sociedade. Por sua vez, algumas atitudes podem ser inconscientes ou podem ser resultado de escala de valores 
culturais de cada indivíduo. De fato, os problemas ambientais que ocorrem nas cidades na realidade são problemas socioambientais, pois é no espaço da cidade que se estabelece e concretizam a interação entre a natureza e a sociedade.

A arborização é o componente ambiental mais visível, contudo a população ainda desconhece a importância da conservação das áreas verdes para a qualidade ambiental do espaço vivido na cidade, uma vez que nesses espaços, principalmente, se efetivam as relações sócio-culturais dos itabaianenses, cujo componente primordial é a disseminação de relações comerciais.

Observações concretas permitem a afirmação de que é o grande percentual de cobertura do solo da cidade por asfalto e cimento, a causa de problemas freqüentes em épocas de chuvas, como as enchentes. Principalmente, em épocas de chuva é comum queixas sobre os danos causados pelos alagamentos em vários pontos de bairros distintos.

Assim, o espaço construído e a insuficiência de áreas verdes no município atuam sobre a temperatura e a umidade. Além disso, a construção e substituição da superfície natural por um conjunto de construções de imóveis aumentam a rugosidade, cujos efeitos mais diretos são: a redução da velocidade do vento e aumento da turbulência, verificados especialmente no bairro Centro.

Percebe-se que a população e autoridades itabaianenses não possuem uma identidade voltada para questões ambientais, isto é, a sociedade não está muito preocupada com as questões ambientais e até mesmo se essas vão influir ou não na qualidade de vida. As preocupações dos cidadãos com a melhora da qualidade de vida estão mais vinculadas aos aspectos financeiros ou materiais, pois a identidade do Itabaianense tem raízes no setor comercial.

Portanto, existe necessidade de difusão da educação ambiental no município como princípio transformador, no qual a co-responsabilização dos indivíduos torna-se um objetivo essencial para promover o desenvolvimento sustentável e não apenas o crescimento puramente econômico. Por isso, aplicar os preceitos da educação voltada para o comprometimento com as questões ambientais implica na necessidade de se ajustar as práticas sociais baseadas no fortalecimento do acesso à informação e à educação ambiental em um ponto de vista integrador.

E, ainda, as derivações antropogênicas de localidades urbanas sobrepujam as preocupações com o ambiente atmosférico, distante da consciência cidadã do que seja qualidade de vida.

\section{REFERÊNCIAS}

AB' SABER, Aziz Nacib. Sertões e sertanejos: uma Geografia humana e sofrida. In: Estudos Avançados, dossiê nordeste seco. Vol.13. USP: São Paulo, 1999.

AYOADE, J.O. Introdução à climatologia para os trópicos. $3^{\circ} \mathrm{ed}$. Rio de Janeiro: Bertrand Brasil, 1991.

FRANÇA, V. L. A \& CRUZ, M. T. S (Coords.). Atlas escolar Sergipe: Eespaço geo-histórico e cultural. João Pessoa: Grafset, 2007. 
GUIMARAES, Mauro. Sustentabilidade e educação ambiental. In: CUNHA, S. B. \& GUERRA, A. J. T. (orgs.). A Questão Ambiental: diferentes abordagens. Rio de Janeiro: Bertrand Brasil, 2003, pp. 81-106.

LIMA NETO, E. M \& MELO E SOUZA, R. Arborização urbana: Gênese e relevância no planejamento territorial. In: Rosemeri Melo e Souza (Org). Território, Planejamento e Sustentabilidade: conceitos e práticas. São Cristóvão/SE: Editora da Universidade Federal de Sergipe, 2009, PP. 55-68.

LORUSSO, D. C. S. Gestão das áreas verdes urbanas. In: Encontro Brasileiro de sobre arborização urbana, 1992. Vitória, Anais... Vitoria, Prefeitura Municipal de Vitoria, 1992, P. 181-185.

MENDONÇA, Francisco. Sistema ambiental urbano: Uma abordagem dos problemas sócioambientais da cidade. In: MENDONÇA, Francisco. (org.). Impactos socioambientais urbanos. Curitiba: Ed. UFPR, 2004, pp. 185-208.

NUCCI, J. C Qualidade ambiental e adensamento urbano: Uum estudo de ecologia e planejamento da paisagem aplicada ao distrito de Santa Cecília (MSP). São Paulo: Humanitas/FFLCH-USP, 2001.

PINTO, Josefa Eliane S. de S. Os reflexos da seca no Estado de Sergipe. São Cristóvão: NPGEO, UFS: 1999.

- Derivações antropogênicas do clima no espaço agrário de Sergipe: um ensaio. Simpósio de Climatologia Geográfica, 7, 2006, Rondonópolis, MT. Anais..., Rondonópolis/ MT: UFMT, 2006.

PINTO, J.E.S de S.; AGUIAR NETO, A. de O. Clima, climatologia e agrometeorologia: uma abordagem interdisciplinar. São Cristóvão/SE: Editora da Universidade Federal de Sergipe, 2008.

RESENDE, W. X \& MELO E SOUZA, R. Concepções e controvérsias sobre áreas verdes urbanas. In: Rosemeri Melo e Souza (Org). Território, planejamento e sustentabilidade: conceitos e práticas. São Cristóvão/SE: Editora da Universidade Federal de Sergipe, 2009, pp. 37-54. 
